\title{
Psychodynamics of self-directed destructive behaviour in adolescence
}

\author{
Adrian Sutton
}

The Government white paper 'Health of the Nation' set a target for reduction of suicide rates by $15 \%$ by the year 2000 . Although the document did not make specific reference to adolescence, it is no less important an issue in this age group than in adulthood since, along with accidental death and malignancy, suicide is one of the most common causes of death in late adolescence and early adulthood and there is an upward trend (Diekstra, 1993; McClure, 1994; Diekstra et al, 1995). How the reduction should be achieved is not clear, since suicide is a rare event which is the culmination of complex processes, and present knowledge does not give a firm foundation for evidence-based practice (Gunnell \& Frankel, 1994).

\section{Prevention}

\section{Publichealth issues}

Eddy et al (1987) asked a group of recognised experts to estimate the likely effectiveness (in reducing adolescent suicides) of interventions directed at different points along the pathway from the existence of a young person at risk of committing suicide, recognition of him/her, the offer and acceptance of treatment, to effective treatment and the prevention of a death. Their results highlighted the uncertainty of the experts in this respect and a reluctance to make statements lest these should prove misleading and potentially detrimental. So, how are child and adolescent psychiatrists to contribute to the agenda of reducing suicide by $15 \%$ ?

Psychological autopsy indicates that, generally, young people who kill themselves have shown previous evidence of mental health problems, often over a long time (Marttunen et al, 1992). Diekstra et al (1995) suggest that target areas should be identifying and treating depression, substance misuse, antisocial behaviour and the impact of suicidal behaviour as experienced in the family (and as presented in the media), alterations in family functioning and structure (particularly intra-family conflict and decreased parental support) and the prolonging of social dependency through adolescence, along with wider societal changes.

Shaffer et al (1988) propose a model with factors on either side of a balance which may either inhibit or facilitate a completed suicide. 'Facilitating' factors apply at the individual psychopathological, interpersonal and societal level, with equivalents on the 'inhibiting' side. This model emphasises the need to attend at all levels through individual case identification, accessibility of help, restriction of access to fatal methods, to sensitivity to representations and portrayals of suicide in the popular media. The above views argue for comprehensive child and adolescent mental health services as a fundamental component of primary preventative measures (Box 1). Such services must be able both to respond directly to the young people and their families and be available to other professionals who may be in a position to recognise difficulty and perhaps assist engagement with mental health services. At present these services are inadequate (Warden, 1997).

\section{Promoting a positive approach}

Many young people who attempt or commit suicide have indicated the seriousness with which they view their situation or the misery they are

Adrian Sutton trained at University College Hospital and the Tavistock Centre, London, before moving to central Manchester in 1986 (Psychiatry Directorate, Winnicott Centre, Child and Adolescent Service, 195-197 Hathersage Road, Manchester M13 0JE). The assessment and management of suicidality in children and adolescents is a major aspect of his current clinical practice. Developing understanding of the psychodynamics of deliberate self-harm and operationalising this for crisis management is a special interest. 
experiencing in the period before the act. Wider understanding of the significance of such communications and ensuring they are taken seriously is important. In the USA, concern for increasing rates of adolescent suicide have led to attempts to develop suicide awareness programmes in schools. Shaffer et al's $(1990,1991)$ findings did not indicate a significant impact in the way hoped for from their approach. However, an important incidental finding was that self-report revealed a higher prevalence of suicide attempts than interview.

Estimates of the ratio of attempted suicide or deliberate self-harm (DSH) to completed suicide vary from 50:1 to 200:1. Adolescents who have previously presented in this way are at greater risk of ultimately completing suicide (Zimmerman \& Asnis, 1995). They need to be highlighted as a key group for recognition of the potential suicide (Eddy et al,1987). Joffe \& Offord (1983) advise against the use of information derived from suicide in adulthood to work with children: caution should also be applied in its application to work with adolescents.

\section{Deliberate self-harm}

\section{Always a serious presenting symptom}

In addition to the risk of completed suicide, young people who deliberately harm themselves have very high rates of psychiatric disturbance and psychosocial difficulties (Harrington \& Dyer, 1993) and the risk of recurrent DSH is high (Kerfoot \& McHugh, 1992). Outcome studies also indicate that long-term difficulties may well occur (Zimmerman \& Asnis, 1995). Clinicians with different theoretical approaches agree on the importance of taking this presentation seriously. For this reason the organisation of professional response to adolescents presenting with self-harm is seen as central in child

Box 1. Suicide prevention: child and adolescent psychiatrists' tasks

Educating policy makers

Public education about the importance of adolescent mental health

Promoting the development of comprehensive child and adolescent psychiatric services

Promoting a positive and sensitive approach to the expression of hopelessness, misery or suicidality by adolescents and adolescent mental health services: previous guidelines by the Royal College of Psychiatrists (1982) and recent proposed revisions underline this.

\section{Intentionality in self-directed destructive behaviour}

\section{Mary had a little lapse}

Mary, a 17-year-old girl took an overdose of prescribed psychotropic medication impulsively after an argument with her sister. She stopped after taking only a few tablets and went to tell her sister (who was downstairs) exactly what she had done and asked her to send for help. On arrival at hospital she made clear her wish to be alive, although she admitted to having fleetingly wished to be dead. Preceding the overdose there had been a few weeks during which she had felt very miserable after an abortion. Mary's parents had supported her through finding out she was pregnant and in the decision to have a termination but there had been increasing arguments between them. Her relationship with her boyfriend had also deteriorated. Mary had consulted her general practitioner who had reassured her that she would gradually feel better and prescribed the medication which she had taken in overdose. Suicidal thoughts and feelings had not been enquired about at that time, but on assessment in hospital were acknowledged as having been present: however, there had not been any plans made to act upon these.

Hawton (1986) suggests eight criteria indicative of serious suicidal intent. These relate to the extent to which the act was planned for, carried out and followed through in such a way as to keep it from the notice of others. By these indicators, Mary's overdose was not taken with serious suicidal intent, yet at assessment she talked about the period of time, albeit very brief, during which she wanted to be dead.

On that occasion, Mary's conscious experience was of having acted, and of having intended to act, in such a way as to be the agent of her own death.

So, is the 'intentionality' of an act defined by the persistence of the wish to achieve a particular outcome over a prolonged period of time, or does 'intent' need to exist only long enough for an act to be initiated (not even necessarily completed) for it to be considered as intended?

\section{What drives the act?}

Ric had attempted to kill himself by hanging. In relation to prior planning, the situation in which 
the hanging had occurred and his mental state presentation at the time of assessment, this was not a 'high/serious suicidal intent' act. However, Ric described the whole process of his previous suicidal thoughts and feelings and how something different had happened in terms of acting upon these on that day. "It was like there were two cars racing along the road", he said, "the suicidal one overtook for a while".

Ric presents his attempted suicide as an alteration in the balance between a 'keeping alive drive' and a 'deadly drive'. This would suggest that rather than considering there to be a single dimension with a full suicidal wish/intent at one end and nil at the other, we need to conceptualise there being two components in tandem. The action which occurs is the resultant of the individual forces behind each and the relative balance between the two.

\section{Darren's going nowhere}

Darren was apathetic when seen on the paediatric ward. He had taken an overdose of drugs but had not brought it to anyone's attention until many hours later. He was prepared to give information about the events surrounding the overdose but seemed rather detached. He said he hadn't particularly wanted to kill himself but he did believe that the drugs he had taken could kill him. So why had he not ensured that he was made safe? In the process of the consultation it appeared that Darren was prepared to accept death as an outcome, feeling that he had little giving him satisfaction in life and plenty that gave dissatisfaction to a degree that was intolerable.

For Darren there was sufficient self-destructive force for an act to occur, followed by a balance without a powerful drive behind either component, leading to inertia: a shift occurred so that attention was obtained, followed by a return to a state of inertia.

\section{Professional impact}

Estimates of the extent to which behaviour is attempted suicide vary. Hawton et al (1982), in a study of motivation in deliberate self-poisoning by 50 adolescents, found $34 \%$ who indicated that an unequivocal wish to die had been present, $42 \%$ who did not mind whether they lived or died and only $24 \%$ who denied wishing to die. The assessing clinicians' estimates were that $14 \%$ had experienced suicidal intent, $18 \%$ were prepared to accept either outcome and $68 \%$ had not wished to die. Agreement between the teenagers and the clinicians occurred in all of the group who did not want to die, but in only five out of the 17 cases where the young person stated suicidal intent.
In discussing the discrepant views of the teenagers and clinicians, Hawton et al (1982) state:

"... [the finding] suggests that 'wanting to die' often provides the only reason for taking an overdose that seems credible or legitimate to the patient. Thus, adolescent self-poisoners may feel so distressed at the time of taking the overdose that they feel as if they want to die, but death is not the (unconsciously) intended outcome of the act.

'Wanting to die' may be the individual's way of legitimising the suicide attempt in his or her own mind."

However, this must be considered alongside the possibility that the professionals' estimates may be affected by unconscious processes in themselves as a consequence of the nature either of work with adolescents (Sutton, 1997a) or in the arena of suicidal thoughts, feelings and impulses (Laufer \& Laufer, 1984; Sutton, 1986) or both.

\section{Communication or enactment?}

A more enlightened approach to suicide during the post-war period led to the idea of self-directed destructive behaviour as a 'cry for help': these were people who needed to be understood, not treated as criminals. This undoubtedly altered the response and provision of resources. Yet it perhaps also presents a new problem: implicit in the phrase is the placing of the act in the interpersonal sphere, that is, as a communication with an expectation of a reasonable person responding with an attempt to help. O'Brien (1986), in a study of 15- to 30-year-olds:

"... gained the impression that for most people it was a private act ... preoccupied with their own distress and pain ... incapable of making contact with other people at the time."

My experience has led to the same conclusion. Mary had communicated her misery and despair to her family and her general practitioner: the overdose came after an argument with her sister and the experience of 'loss' of the relationship which she felt had always been there when all else failed. In the intensity of this and her overall context, she had felt totally alone in a timeless space in which the feelings would be forever and intolerable. The attempt to end it all occurred: hope in the efficacy of relationships then returned.

\section{A barren landscape}

Kevin had taken an overdose of analgesics. At an out-patient appointment with his whole family a fortnight later Kevin's mother asked the 
psychiatrist whether Kevin had done it to get at her. The psychiatrist suggested she ask Kevin himself. He replied:

"No, Mum, I didn't do it to get at you. You weren't in my mind ... there was no-one in my mind when I did it."

Kevin's overdose had not been an attempt at communicating or a conscious effort to seek assistance.

In discussing the discrepancy between patients' and clinicians' assessments of suicidal intent, Hawton comments that the cry for help hypothesis may be misleading. He further quotes White (1974):

“... episodes may still have an appeal function, but the appeal is more often interpersonal than directed to any outside helping agency" (Hawton, 1996).

The position taken in this paper is to suggest that this view needs to be challenged further. To turn the specific act of DSH into an interpersonal event may represent a denial of the experience of the adolescent of having been in a world in which there was no help which could come from relationships to relieve the experience of unbearable suffering in the self.

The act is often communicated after the event but unless it is carried out in the presence of a person who can reasonably be expected to respond to prevent the act or its potential harmful effects, then it cannot be considered a cry for help.

Contrast the following with examples given earlier.

\section{Pain relief}

Greg looked rather miserable when he went into the pharmacist's and asked for a bottle of analgesics. When given them he proceeded to take an overdose in front of the salesperson. Attempts to stop him failed and an ambulance was called for.

Cries for help are rarely so flamboyant although a young person putting themself on a bridge parapet or the top of a tall building may be equally demanding of attention, even if not necessarily so seeking of attention.

\section{Seeking a helping hand}

The relationship between Joan and her mother had always been poor. After yet another disagreement, Joan's mother screamed at her that she wished Joan did not exist. Joan went and got some tablets from the medicine cabinet and went back to her mother. She began taking them in front of her mother who made no attempt to stop her and only sought medical help much later. Joan reported at assessment that she had hoped her mother would stop her.

\section{A brief clinical history of time}

The preceding consideration of intentionality in relation to suicidality and communication has been presented for very practical reasons. The ways in which our thinking is structured as we approach each new or old person on each presenting occasion contributes to the presentation of past and future. Our beliefs about the nature of intentionality and communication are fundamentally important in this respect. The potential for establishing a therapeutic alliance requires that the clinician is able to demonstrate to the person, implicitly and explicitly, that her/his understanding is being shaped sufficiently by the person in front of them, rather than the person in front of him/her being shaped to fit the clinician's understanding. Given the significance in adolescence of issues relating to identity and the conflicting currents in needing the assistance of adults, this is an imperative. To choose an objective measure of time as the indicator of intention and personal experience is incorrect.

The use of the term 'impulsive' implies both that the act occurred in the absence of the usual mental activity which modulates physical activity, and without previous planning; but how long would planning need to have been taking place before it was considered as significant in terms of defining intent - long enough to pick up a knife and stab or cut; long enough to open a bottle, take tablets out and start taking them; or long enough to go out to obtain the means, write the suicide note and wait until nobody is around? Similarly, to translate the fact that an act was communicated after the event to having been a communication in itself is incorrect (Box 2).

The nature of adolescence, in terms of the potential for dramatic variability in emotional intensity and impulse control, means that we have to be able to step into a different arena in which time is relative and no longer an absolute. In this place we may have to make a quantum leap; clinicians have to realise that some rules may serve well at certain times, but given different criteria, a different set of rules apply. While adults and adolescents may often share the experience of time, at other times this is not so. What must be emphasised is the sense of 'foreverness' of the intolerable state from which the young person is trying to escape.

\section{What does it take for a suicide attempt to occur?}

No specific indicators exist to predict which adolescents will take overdoses. Factors which need 
Box 2. A cry for help or a statement of feeling beyond help?

Interpretation of suicidal and communicatory function of the behaviour may be flawed because of misunderstandings about the experience of emotion and time. The wish to be dead, or having wished to be dead, may be underestimated: an intensely internal experience translated into an interpersonal act.

to be considered extend from the intrapsychic and interpersonal to the situational/contextual. Suicidal thoughts are very common, with reports of up to $62 \%$ from an anonymous survey (Zimmerman \& Asnis, 1995). Berman \& Jobes (1992) review the specific quality of emotions and cognitions which may come together in the act of self-harm; hopelessness, anger and aggression are of particular importance. They also describe an interesting model for suicide proposed by Shneidman (1967) in which three dimensions - pain, perturbation and press - are used. Each can be scored on a five-point scale of severity: the '5-5-5' combination represents the suicidal combination

"caused by a synthesis of emotional energy (upset) [perturbation], acute subjective intrapsychic pain, and overwhelming external pressures."

If the fourth dimension, time, is included, a suicide attempt can be seen as the effect of this combination assuming ascendancy for long enough for the act to occur. Sutton (1997b) suggests the necessary components are: the idea of death held as the only conceivable solution; for a sufficient length of time; in the presence of available means (viewed subjectively as potentially lethal).

This can be summarised as the means, the motivation, and the moment(s) of madness' (Box 3; 'four Ms' complementary to Shneidman's 'three Ps').

\section{Crisis assessment and management}

In managing the acute crisis of an act of self-harm we are, in most cases, simultaneously having to see whether we can come to know the individual, assess the internal and external resources available to them, approach them in a way which will make
Box 3. Minimal requirements for attempted suicide

The 'four $\mathrm{Ms}^{\prime}$ - means, motivation, moment(s), 'madness'

engagement likely and formulate the factors which may affect that person's safety, particularly in relation to the risk of repetition.

Research findings do not guide us towards one specific treatment approach. Descriptions of some approaches drawing on varying theoretical models can be found in Hawton (1986), Hollis (1987), Reder et al (1991), Berman \& Jobes (1992), Zimmerman \& Asnis (1995), Kerfoot et al (1995), Brent (1997) and Sutton (1997b).

The key issue in assessment must be an appreciation of the multiple influences which may have come to bear in producing the act. Seeking a linear cause will mislead. Drawing on the concept of 'sensitive dependence on initial conditions' from chaos theory (Gleick, 1987), one can understand that an apparently small alteration, even in one variable of apparently little significance, may produce dramatic change in a system. In other words, the straw which broke the camel's back did not have to possess great mass itself: it achieved its effect as a consequence of the significance of its arrival at a particular place at a particular time (it could be the lightest object placed upon the camel's back).

Continuing pressure to escape unbearable emotional states in a situation which no resources in the self or others are felt to affect and to which no end can be seen, is the most concerning constellation. Such pressure may come from the inner world through depression, misery, psychosis or other mental state abnormality: drug intoxication leading to reduced ability to contain such mental states may have a similar effect. States of high arousal as a result of a sense of lack of safety in the external world, for example as a consequence of abuse past, present or at risk of continuing, are of equal concern.

Whichever theoretical model guides practice, an essential practical element is that assessment can be carried out in a setting in which the clinician can, while ensuring the safety of the young person, adequately assess mental state, the global functioning of the young person and the context of care from which they have come. For these reasons the recommendation of the Royal College of Psychiatrists (1982) is for admission to a general medical setting in the immediacy of presentation, even if no physical treatment is required. 


\section{Reducing future risk}

Prediction of the future risk either of attempting or completing suicide remains difficult. Presenting an index for predicting suicide attempts in depressed adolescents, Kienhorst et al (1991) cite Motto et al (1985) in describing the problems inherent in trying to move between the individual and the general:

"With a population of one, risk prediction based on clinical judgement can be individualised but validation is not possible. By estimating risk in a large number of subjects, the accuracy of individual risk estimates is reduced but validation becomes feasible."

Previous suicidal behaviour and the presence and severity of suicidal ideation are the major factors which have been identified as predictive, but suicidality varies in intensity over time (Hoberman \& Bergmann, 1992). It is probably better, therefore, to formulate the prognosis in terms of the contingencies thought likely to increase/decrease the presence of suicidal thoughts and feelings and influence the individual's ability to resist acting on these. The formulation thus needs to contain an appreciation of mental state: general egofunctioning in terms of strengths and deficits - the responsiveness and ability of those in a position to try to ensure the young person's safety when he/ she is not able to do this for him/herself or might be showing signs that decompensation may be occurring (an auxiliary ego). Alternative care arrangements may be indicated either in terms of the young person needing to live outside their family for a time or perhaps requiring psychiatric nursing care. In respect of the latter, it is striking in reading the literature how the option of in-patient admission after attempted suicide appears to be more available in the USA than the UK.

In the absence of a framework for evidence-based practice, a reasonable aspiration would be to seek more formal, detailed descriptions and analysis of clinicians' practice. This could inform the debate on examples of best practice and provide a basis for research and audit. Two key markers for discrimination could be repetition rate and, in view of the often reported difficulty in engaging these young people, a simple but important starting point would be examination of rates of attendance for follow-up and the extent to which discharge was planned, with the individual and the clinician in agreement (and also not simply governed by the availability of resources to continue treatment).

No approach will provide the safety of 'certainty' in making the formulation. Tolerating this uncertainty and managing other countertransference issues is a central theme in this field and makes considerable demands upon clinical staff. The planning of services must include consideration of the amount of work with suicidal individuals which practitioners can reasonably undertake, and what support is available to them in order to conduct the work (see Box 4) (Kernberg, 1994).

\section{Deliberate self-harm: a traumatising event}

A further area for consideration in research is what the impact of having acted upon suicidal thoughts, feelings and impulses is upon the developing young person. Laufer \& Laufer (1984) see it as:

“... constituting a traumatic experience ... The effect of this trauma creates the need for the adolescent to repeat and re-enact situations that are dynamically equivalent to a suicidal act."

I was drawn back to this issue when reading descriptions of post-traumatic debriefing in realising that many similarities existed between the process recommended and this approach to attempted suicide, particularly in ensuring a focus is maintained on obtaining a clear account of the incident, and the sequence of events leading up to and following it.

\section{Other victims of suicidality}

Hawton (1986) describes the impact of a suicide on family members and other people in the young person's life. Provision needs to be made for assessing their needs and offering help. Perhaps this thinking also needs to be extended into the arena of attempted suicide and other DSH. In managing the crisis it would be wrong to consider these others only as potential resources, although necessity may mean this will have to predominate in the immediate situation. The young person's future may well depend upon the assistance these others

Box 4. Components of services for deliberate self-harm

Services need to take account of the impact of suicidality and suicidal behaviour on - the young person, the carers, other people in key relationships, the professionals working with suicidal young people 
receive in assimilating the events, not only the help taken up by the adolescent herself.

By its very nature suicidality will remain a complicated field. It causes difficulty in thinking and communicating which can be illustrated by a subtle ambiguity from Stengel's seminal writings (1964):

"Gandhi's fasts presented the most persistent use of the threat of suicide for political purposes. By taking it seriously, the British administration prevented a great deal of bloodshed. It has been said that it surrendered to blackmail, but everybody faced with a serious threat of suicide has to yield to a certain degree, just as much as a man threatened with a gun, unless he wants to be killed."

\section{References}

Berman, A. L. \& Jobes, D. A. (1992) Adolescent Suicide: Assessment and Intervention. Washington, DC: American Psychological Association.

Brent, D. A. (1997) Practitioner review: the aftercare of adolescents with deliberate self harm. Journal of Child Psychology and Psychiatry, 38, 277-286.

Diekstra, R. F.W. (1993) The epidemiology of suicide and parasuicide. Acta Psychiatrica Scandinavica Supplementum, 371, 9-20

-, Kienhorst, C. W. M. \& De Wilde, E. J. (1995) Suicide and suicidal behaviour among adolescents. In Psychosocial Disorders in Young People: Time Trends and Their Causes (eds M. Rutter \& D. J.Smith), pp. 686-761. Chichester: John Wiley and Sons.

Eddy, D. M., Wolpert, R. L. \& Rosenberg, M. L. (1987) Estimating the effectiveness of interventions to prevent youth suicides. Medical Care, suppl. 23, S37-S63.

Gleick, J. (1987) Chaos: Making a New Science. London: Cardinal.

Gunnell, D. \& Frankel, S. (1994) Prevention of suicide: aspirations and evidence. British Medical Journal, 308, 1227-1233.

Harrington, R. \& Dyer, E. (1993) Suicide and attempted suicide in adolescence. Current Opinion in Psychiatry, 6, 467-469.

Hawton, K. (1986) Suicide and Attempted Suicide Among Children and Adolescents. London: Sage.

-, Cole, D., O'Grady, J., et al (1982) Motivational aspects of deliberate self-poisoning in adolescents. British Journal of Psychiatry, 141, 286-291.

Hoberman, H. M. \& Bergmann, P. E. (1992) Suicidal behaviour in adolescence. Current Opinion in Psychiatry, 5, 508-517.

Hollis, P. (1987) The management of adolescent overdose-a systems approach. Journal of Family Therapy, 9, 161-175.

Joffe, R. T. \& Offord, D. R. (1983) Suicidal behaviour in childhood. Canadian Journal of Psychiatry, 28, 57-63.

Kerfoot, M. \& McHugh, B. (1992) The outcome of childhood suicidal behaviour. Acta Paedopsychiatrica, 55, 141-145.

-, Harrington, R. \& Dyer, E. (1995) Brief home-based intervention with young suicide attempters and their families. Journal of Adolescence, 18, 557-568.

Kernberg, P. F. (1994) Psychological interventions for the suicidal adolescent. American Journal of Psychotherapy, 48, 52-63.

Kienhorst, C. W. M., De Wilde, E. J., Diekstra, R. F. W., et al (1991) Construction of an index for predicting suicide attempts in depressed adolescents. British Journal of Psychiatry, 159, 676-682.

Laufer, M. \& Laufer, M. E. (1984) Adolescence and Developmental Breakdown: A Psychoanalytic View. New Haven, CT: Yale University Press.

Marttunen, M. J., Aro, H. M. \& Lonnqvist, J. K. (1992) Adolescent suicide: endpoint of long term difficulties. Journal of the American Academy of Child And Adolescent Psychiatry, 31, 649-654.

McClure, G. M. G. (1994) Suicide in children and adolescents in England and Wales 1960-90. British Journal of Psychiatry, 165, 510-514.
Motto, J. A., Heilbron, D. C. \& Juster, R. P. (1985) Development of a clinical instrument to predict suicide risk. American Journal of Psychiatry, 40, 148-154.

O'Brien, S. (1986) The Negative Scream: A Story of Young People who Took an Overdose. London: Routledge and Kegan Paul.

Reder, P., Lucey, C. \& Fredman, G. (1991) The challenge of deliberate self-harm by young people. Journal of Adolescence, 14, 135-148.

Royal College of Psychiatrists (1982) The management of parasuicide in young people under sixteen. Bulletin of the Royal College of Psychiatrists, 6, 182-185.

Shaffer, D., Garland, A., Gould, M., et al (1988) Preventing teenage suicide: a critical review. Journal of the American Academy of Child and Adolescent Psychiatry, 27, 675-687.

-, Vieland, V., Garland, A., et al (1990) Adolescent suicide attempters: response to suicide prevention programs. Journal of the American Medical Association, 264, 3151-3155.

-, Garland, A., Vieland, V., et al (1991) The impact of curriculumbased suicide prevention programs for teenagers. Journal of the American Academy of Child and Adolescent Psychiatry, 30, 588-596.

Shneidman, E. S. (1967) Bulletin of Suicidology (No.1). Rockville, MD: The National Institute of Mental Health Centre for Studies of Suicide Prevention.

Stengel, E. (1964) Suicide and Attempted Suicide. Harmondsworth: Penguin.

Sutton, A. (1986) Management of teenagers who take overdoses. Update: The Journal of Postgraduate General Practice, 3, 144-151.

- (1997a) Authority, autonomy, responsibility and authorisation: with specific reference to adolescent mental health practice. Journal of Medical Ethics, 23, 26-31.

- (1997b) Self destructive behaviour - dare we take it at face value? Resource Network for Adolescents Newsletter, in press.

Warden, J. (1997) Young people's mental health neglected, say MP's. British Medical Journal, 314, 849.

White, H.C. (1974) Self-poisoning in adolescents. British Journal of Psychiatry, 124, 24-35.

Zimmerman, J. K. \& Asnis, G. M. (1995) Treatment Approaches with Suicidal Adolescents. New York: John Wiley and Sons.

\section{Multiple choice questions}

1. Completed suicide in adolescence:

a is associated with depression, substance misuse and exposure to suicidal behaviour in the family

b can be reduced in frequency by the inclusion of suicide prevention teaching in the national curriculum

c occurs with about one-tenth the frequency of attempted suicide

$\mathrm{d}$ is the most common cause of death in late adolescent and young adult males

e is commonly preceded by previous suicide attempts.

2. In assessing deliberate self-harm patients:

a only rarely does there appear to have been suicidal intent in the act

b psychiatric evaluation is best carried out by out-patient attendance after the medical or surgical effects have been treated

c the concept of 'sensitive dependence on initial conditions' can help in understanding the precipitating events 
d the clinician's beliefs about suicide may affect the clinical process

e instruments developed for work with adults can be reliably used in assessing adolescents.

3. In predicting future risk:

a previous suicidal behaviour is a good indicator of increased future risk

b where physical abuse is occurring it is unlikely that alternative care arrangements will affect the outcome

c Kienhorst's Suicide Behaviour Index is a reliable predictive tool

d of suicidal behaviour consideration of the personal and interpersonal factors impinging on the young person is essential

e hopelessness and anger indicate higher likelihood of recurrence of suicidal behaviour.

4. In providing deliberate self-harm psychiatric services for adolescents:

a assessment and treatment is ideally carried out in-patient psychiatric units

b recognition of the impact upon family and other people in important relationships with the adolescent should be included

c account should taken of the impact upon professionals of working with suicidal youngsters by defining limits to the amount of work carried out in this arena

d clinical management protocols developed for adults are appropriate for use with adolescents

e completed suicide rate is a suitable measure of outcome for audit purposes.
5. Directions for future research:

a attendance for follow-up and engagement in treatment programs may be useful measures for comparing different approaches to crisis management

b the impact of deliberate self-harm on the young person's personality development needs further investigation

c the impact on deliberate self-harm of programs for substance misuse is unlikely to be a fruitful area

$d$ the effect of extended dependence in adolescence will be readily identifiable as a variable

e countertransference effects on the development of a therapeutic alliance need further investigation.

\begin{tabular}{|c|c|c|c|c|}
\hline \multicolumn{5}{|c|}{ MCQ answers } \\
\hline 1 & 2 & 3 & 4 & 5 \\
\hline a $\mathrm{T}$ & a $F$ & a $T$ & a $F$ & a $\mathrm{T}$ \\
\hline b $\mathbf{F}$ & b F & b F & b $T$ & b $\mathrm{T}$ \\
\hline c $F$ & c $\mathrm{T}$ & c $\mathrm{F}$ & c $\mathbf{T}$ & c $\mathrm{F}$ \\
\hline d F & d $\mathrm{T}$ & d $T$ & d F & d F \\
\hline e $T$ & e $F$ & e $T$ & e $F$ & e $\mathrm{T}$ \\
\hline
\end{tabular}

